\title{
Process innovation with lightweight IT at an emergency unit
}

\author{
Egil Øvrelid \\ University of Oslo \\ egilov@ifi.uio.no
}

\author{
Marit Røed Halvorsen \\ Oslo Municipality, Health Section \\ marit.roed.halvorsen@hel.oslo.kommune.no
}

\begin{abstract}
In this paper, we are studying the role of lightweight IT in process innovation. Our research question is how can lightweight IT support process innovation within an established e-health information infrastructure? Our empirical evidence is a qualitative case study at a primary care emergency service in Oslo. We provide two contributions. First, applying the lens of business process innovation to the literature on information infrastructures, we retain the value of the installed base, while we at the same time ad speed to the implementation project. Second, we demonstrate the role of lightweight technology in improving logistics and message interaction within and between health units. The lightweight technologies availability on the commercial market makes acquisition and implementation faster. Based on this, we briefly suggest a "bypassing strategy" where a new layer of technology is built separately from the existing infrastructure in order to effectively address process innovation efforts.
\end{abstract}

\section{Introduction}

The modern society of today where the population is increasingly concerned about health, add an extra burden to the organization of health services, their accessibility, as well as the cost for providing these services $[1,2,19,31,32]$. The Healthcare System has traditionally been praiseworthy occupied with qualitative patient care, and the IT systems that surround clinical practice has primarily concentrated on clinical processes with the mission of securing practice. A drawback of this orientation is that hospitals are struggling with logistics both internally and externally, as clinical systems focus on optimization of clinical practice, not on horizontal process support [6]. A usual complaint from patients is thus that while the treatment was excellent, the coordination between units was slow, the waiting time long, and feedback almost nonexistent [3, 4]. This is partly caused by the significant difficulties in streamlining the supply chain [5]. One of the main consequences of these challenges is that innovation efforts in the health sector once initiated tend to lose steam, and slow down $[19,31]$.

Addressing these challenges requires the optimization through redesign of processes and digitalization of IT, and modern innovative "lightweight" IT have shown promising tendencies in establishing process improvement $[10,27,28]$. We will follow-up on these promising studies by looking into the role of lightweight technologies in process innovation. Accordingly, this research attempt to answer the following research questions: How can lightweight IT support process innovation within an established e-health information infrastructure? This perspective includes looking into the role of the organizational installed base and the role of innovative technology in process innovation.

We proceed by related research from the field of information infrastructure [7]. Incremental and path dependent change has been more central than process innovation in this literature. We then move on to describe Hammer and Champys [29, 30] important and original insight in how to use IT to transform modern organizations business processes, but balance it with a more 'nuanced' approach provided by Melao and Pidd [34]. We adopt the term "installed base" [7] from information infrastructure literature in order to frame and understand the importance of retaining some aspects of the pre-existing sociotechnical layers of rules, regulations, and technological tools in process innovation initiatives in the healthcare system.

\section{Information infrastructures and lightweight IT}

We see information systems as information infrastructures and are interested in how they evolve. Information infrastructures are sociotechnical layers of technology, people, regulations, policies, tools and facilities formed over time $[7,8,13,33]$. The historically accumulated installed base, which is a central aspect of the infrastructures nature, have a strong conservative influence [8]. This means that all 
change and innovation has to consider the installed base. Information infrastructures have to be carefully cultivated $[18,33]$. Bootstrapping is a particular form of cultivation in that it focus on usefulness, and that change has to be carefully performed step-by-step [7, 33]. A prerequisite for change is thus that the existing conditions are understood and taken into account. This can make process innovation challenging and slow. Information infrastructures may turn into path dependent silo structures which resists external innovation $[8,13,33]$. This resistance is also conditioned by power in that it is "driven by IT professionals, enabled by systematic specification and proven digital technology, and realized through software engineering" [10:2]. Bygstad [10] label this regime "heavyweight IT".

Process innovation initiatives interested in relatively fast results [15] will have to look for new ways of avoiding or changing the existing regime, and an emerging stream within IS research is the field on Internet-of-things, tablets, smartphones and whiteboards. Bygstad [10] conceptualize this as "lightweight IT". Important features with lightweight IT is its mobile and remote characteristics enabling system access through apps implemented on handheld devices, or automation of white-collar work through interfaces for enabling easier implementation of service automation tools $[10,11,12]$.

Lightweight IT is not only a technology but also a knowledge regime with at least three central characteristics. One is the nature of the artefact, its usability, its occupation with improving processes and its easiness in implementation. This technology have according to [10] the ability to bypass the existing infrastructure when it is implemented. The second characteristic is the providers' ability to quickly follow up pilots, and implementations, so that users and organizations may experiment on and test new functionality. Finally, the third, which is the acquisition opportunity, the availability of the product on the commercial market [10].

In this paper, we look at a particular case of lightweight IT, electronic whiteboards, and its impact on change processes. This has been done before. The literature on computer supported cooperative work, human-computer interaction, medical informatics and health informatics, demonstrates the mediating ability of electronic whiteboards across practices [16, 17]. Through improving the visual overview [20], whiteboards serves a coordinative function [21, 26]. The findings from these studies highlights the whiteboards adaptability to a complex practice $[20,22$, 23, 24], more than cross-sectional information flow. These findings also address technical solutions developed in-house and thus not made available on the commercial market. We are interested in two other aspects of lightweight technology in process innovation initiatives. First we shed light on the role of commercially available innovative technology and its impact on process innovation initiatives. Second we investigate the electronic whiteboards role in improving horizontal processes within or across departments. To inform our empirical case we use the process innovation literature, which helps us identify central business processes and their characteristics

\section{Process innovation}

Business Process Reengineering's (BPR) main message was that organizations have to remove manual work, and use information technology to radically innovate end-to-end (horizontal) processes [29, 30]. Hammer [30] outlines six principles for implementing end-to-end processes using the power of IT. First, organize around outcomes instead of tasks. Second, those who use the output should perform the process. Third, make sure that real work that produces the information replaces information-processing work. Fourth, link instead of integrate parallel activities. Fifth, connect performance and decisions, and build control into the process. Sixth, capture information once, and at the source.

Hammer and Champy emphasized the need to understand the services delivered to the customer in their totality, and modern technology's ability to exceed existing barriers in enabling organizational change. BPRs lack of organizational dimensions and the tendency of top down managerial sidedness was, however, a significant shortcoming. As processes are complex organizational phenomena where workers attached to different parts of the organizations are collaborating, a more nuanced view of processes, and a systematic approach to understand them, was needed [34]. A weakness in the BPR approach is the way they ignore the importance of historical learning and adaptation as well as the existence of rules, regulations, and technological components that has gradually accumulated. In the literature on information infrastructures, this "installed base" [7] is an important point of departure, and acknowledges the step-by-step emergence of collaborative networks in organizations $[33,34]$.

Melao and Pidds [34] four perspectives on end-toend processes, combine a top-down management perspective with a heterogeneous bottom-up understanding of organizational change. In every organization there will be processes which can be streamlined and improved pretty fast, while other more complex processes will take longer time. 
Their first perspective business processes as deterministic machines concerns breaking tasks into well-defined operations performed rigorously without deviations. This requires well-understood processes where intervention based on human knowledge is minimized. The second perspective, business processes as complex dynamic systems, regards the dynamics and interactive features of processes. Neither in this perspective is human characteristics and human communication seen as important feedback mechanisms when adjusting system performance. It is thus most appropriate on welldefined processes and tasks that require limited adjustment. The third perspective, business processes as interacting feedback loops includes interactions with the wider environment. Decision-making based on feedback gives a more bureaucratic approach where human actors must intervene in particular situations to ensure that processes go ahead according to policies and other criteria. This perspective fits well to foster learning through the identification of information flow and critical decision points, as well as the activities that go along with it. The fourth perspective, business processes as social constructs emphasize processes as made and enacted by actors with special knowledge, different values, expectations and (possible hidden) agendas. The knowledge related activities requires wider value-related frames of interpretation. Although some standardization is necessary, the autonomy of work is important to enhance learning and improved understanding.

In summary, the early BPR literature is still very relevant as a source for process innovation, and important when innovating sociotechnical information infrastructures. As changes in health care settings and educational institutions should result from negotiations and compromises, the installed base has to be taken into account [7, 13, 33, 34]. In Melao and Pidds approach, this perspective is included but it is not clear in what way the installed base influence the process modeling. Nor do they elaborate on activities associated with digitalizing business processes.

In section 5 and 6 we describe and analyze the consequences of process innovation in a health care setting where the installed base has to be taken into account, but also how process innovation may improve business processes using digital technology. First we describe our methodological approach.

\section{Method}

In 2010, the Health South East region in Norway decided to shut down Aker Hospital as a part of the Oslo University Hospital merging. Protests from the citizens kept the hospital open, and in 2016 Health
South East announced that Aker is a part of their future plans. The SAMKAD project (Interaction at KAD) established in 2014 started as a project for improving internal capacity utilization, and then became a part of a bigger initiative to improve interaction between health units. SAMKAD address a challenge outlined in the national coordination reform, which says that it is "particularly important to ensure good coordination when the responsibility for the patient moves between hospitals and municipalities, and between departments and units within hospitals and municipalities. Good cooperation and relocation to local medical centers can help it" [35]. Nevertheless, several reports are pointing at difficulties in the current interaction between primary and secondary sector [25], difficulties caused by poor communication $[14,39]$.

SAMKAD has gradually turned into a complex project where AKER collaborate with 4 hospitals, 60 nursing homes in 15 neighborhoods and in total 660 general practitioners.

\subsection{Data Collection}

Our research approach is a qualitative case study [9] inspired by engaged scholarship [36, 37]. In this type of research, the informant's role is not only about verification of factual data, but also in constructing the narrative and in some cases to be a qualified participant in discussing theoretical and practical implications [37]. In this framing research becomes a collaborative approach between knowledgeable researchers and practitioners that together secures and improves the research findings $[36,37]$. One of the authors of this paper was central in the process of acquiring the technology as well as the preparation and implementation of organizational changes. We used data from the longitudinal implementation project that lasted two years to reconstruct planning and implementation of the technology.

From November 2015 to January 2017, we collected data using qualitative methods and performed in total 20 interviews; 9 with clinicians, 7 with project leader, and 4 with technical expertise. In order to investigate the technological impact on the organization we had three rounds of observations (around $25 \mathrm{hrs}$.) over a period of one month. We followed up with new interviews as well as analyzes of around 20 documents on workshop results, treatment regulations, political requirements as well as technical descriptions.

\subsection{Data analyzes}

The studies core interest relates to the ongoing debate 
on differences between the classical EPR systems, their change difficulties, and the innovative technology to improve this $[10,12]$. We started by asking project managers about the acquisition process and the performance of the supplier during the implementation and follow-up. We also asked how they used existing resources like role descriptions, regulations and technological tools when they planned and implemented the technology. During the study the role of SINTEF, an expert organization on industrial processes, was emphasized. SINTEF and SAMKAD created a "24 hrs. at KAD" visual map which gave KAD a way of expressing and understanding their existing processes and to identify significant challenges in the way they worked. We asked project management and section managers how they organized the planning and implementation phase, and the role of the clinicians in this activity. During the fieldwork we asked doctors and nurses questions like: have the whiteboards changed your practice in any way? Have you gained anything from this change? Based on this we established a chronology of the projects development (step 1 in table 1).

Table 1: Data analyses

\begin{tabular}{|l|l|l|}
\hline Step & Description & Output \\
\hline 1 & $\begin{array}{l}\text { Establishing a chronology } \\
2014-17\end{array}$ & Section 5 \\
\hline 2 & $\begin{array}{l}\text { Identified five challenges } \\
\text { and three development } \\
\text { phases }\end{array}$ & Section 5 \\
\hline 3 & $\begin{array}{l}\text { Analyzing SAMKAD we } \\
\text { identified 4 aspects of } \\
\text { process innovation }\end{array}$ & Section 6 \\
\hline 4 & Two contributions & Section 7 \\
\hline
\end{tabular}

We identified five challenges addressed in three phases (step 2 in table 1). Using Melao and Pidd [34] we identified 4 aspects of process innovation (step 3). Combining [34], [7] and [10] we provide two contributions (step 4). Our data show that Hammer and Champys [29] original scope is still very relevant, and that Melao and Pidds [34] four perspectives on business processes extends Hammer and Champy in taking the impact of organizational and technological legacy into account. We proceed by describing our case study, before we analyze the case using the lens of process theory.

\section{Process innovation at Aker}

Following Hammer and Champy [29] process innovation is about removing bottlenecks, manual work, and double work in order to facilitate horizontal performance. Aker had several practical challenges they wanted to solve in order to improve their internal performance and consequently enable process innovation. Their process innovation list derived from our data collection and analyzes included:

- Improving the routines for patient admission, and discharge.

- Improving the overview so that the physician on duty can find and book available rooms.

- Providing kitchen and cleaning personnel with information on meals, dietary requirements and room numbers.

- Improving communication during shifts of clinical personnel.

- Improving the interaction with the city neighborhoods to reduce amount of time used for message writing and phone conversation afterwards.

This may seem straightforward but SAMKAD needed to carefully design all the new processes and how ICT systems should be used to support them. They divided the project into two parts: (1) Improving internal logistics, and (2) improving interaction with city neighborhoods through more effective message exchange. In phase 1 and 2 we briefly portray the process of acquiring the technology, and the way SAMKAD worked to improve internal processes. Then in phase 3 we describe SAMKADs solution to improve the interaction with city neighborhoods.

\section{Phase 1: Acquiring whiteboard technology and analyze the existing processes}

At Aker emergency unit (KAD), they had difficulties in keeping up with the pace of arriving patients and treatment requirements. Their process innovation initiative started with a parallel process of defining software requirements, and analyzing existing processes. The project of SAMKAD was established to address this. The project managers at SAMKAD were disappointed with the lack of interest from the existing EPR vendors to participate in the change process. The existing systems needed a lot of modification to enable a more efficient process support, as "static systems are not suitable in an efficient production," (clinician). Accordingly, SAMKAD had to apply for external funding, both for acquiring technology and for establishing and implementing the project. One of the project managers had worked with a whiteboard and mobile supplier called Imatis in an earlier project, and initiated a cooperation with them. SAMKAD implemented Imatis technology after only three months, first 
separated from the existing information infrastructure. Usually changing the digital infrastructure takes months sometimes years. To fulfill health security regulations and to enable cooperation between KAD, Imatis technology and Oslo Municipality, Imatis moved their cloud from Amsterdam and into the technological regime of Oslo Municipality. Oslo Municipality then granted access to Imatis installations between city districts of Stovner, Østensjø and KAD so that information could be exchanged using similar formats.

SAMKAD and SINTEF, an expert organization on industrial processes, developed a detailed analyzes of the existing treatment processes and called it " $24 \mathrm{hrs}$ at KAD". The map was divided into two parts, separated by a horizontal timeline in the middle. The upper parts dealt with requirements expressed by the patients, while the lower parts of the map described clinical activities and concerns. The map displays in detail both important and more regular concerns. Through the visualization SAMKAD was able to identify 'the peak', a certain point during the day when patients are admitted while the discharge of the patients lags behind, making a congestions of patient concerns and clinical activities. The result was that potentially seriously ill patients had to wait.

The work on designing the map was a collective effort where approximately 25 workers from several departments participated. The collaboration enabled a better understanding of the reasons for the occurrence of 'the peak'. Through the workshops, SAMKAD identified several areas of improvements. The project leader emphasize the collective effort: "We have a high degree of employee involvement. This is tremendously challenging, but it raises the quality of our services." The work and the analyzes leading to the visual map enabled SAMKAD to look for processes which could be digitalized relatively fast and identified the ones related to patient admission, discharged patients, challenges related to work shifts, and exchanging effective information between KAD and other health units.

\section{Phase 2: Using Whiteboard technology to improve internal processes}

After the comprehensive analyzes of activities during 24 hours at KAD, SAMKAD wanted to improve selected processes. Imatis Whiteboard was installed after three months. It is an agile contrast to the classic record systems. "The classic systems are very slow"..."very difficult to use to improve efficiency" (doctor)..."they don't harmonize with the way we are working", and "are best to use when working with one patient at a time" (nurse). The doctor sums it up by saying, "our challenges have different requirements", and "the collaboration with Imatis gave benefits quickly". Patients arrive at KAD from several sources (left squares of figure 1). The physician on duty decides the patient admission to Aker, and select KAD ward. Two examples (2A and $2 \mathrm{~B}$ ) describe areas where whiteboard technology has influenced the process, and the result of this.

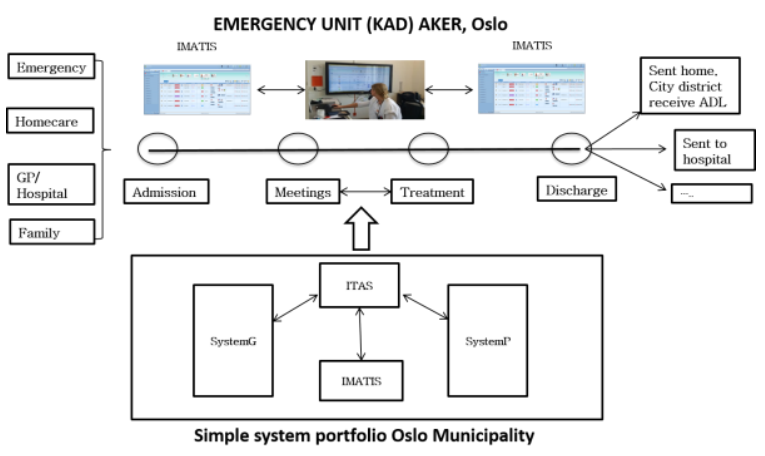

Figure 1: Patient flow and technical regime

\section{A. Admission and discharge}

The physician on duty is writing record notes in SystemP when her phone rings. She receives a request for admission to KAD. The doctor looks up the patient in SystemP, asks some questions about the general condition of the patient, and chooses a unit for the patient admission. She registers the information in SystemP and in Imatis. In Imatis the field "Registered" is marked. The nurses at the receiving unit reads the information, clarifies the room, and make sure that the necessary resources are booked. "This is a considerable improvement, especially the registering and notification that a patient is arriving," the doctor says. Earlier they had to write paper notes and give it to the caretaking nurse by hand. If the physician on duty was positioned in another unit, this activity could take time. Now everyone in the department can immediately see the information displayed on the whiteboards. The same applies to discharge of patients. Since KAD is an emergency unit, with shortterm admissions, it is very important to have overview of the internal resources. The whiteboard technology visualizes the availability of rooms and other resources. Cleaning and kitchen personnel have access to their own 'view', enabling a more efficient planning of basic services. Nurses and clinicians including the physician on duty can now answer incoming requests right away.

\section{B. Morning department meetings}

Since the whiteboards display patient information, including responsible clinician and treatment status, they are a central resource in the morning department 
meetings. Management uses the meeting to repeat general focus on treatment areas. The night nurses use whiteboards to update the day shift on patient statuses. It is as an example very easy to update the patient lists by using drag and drop functionality, when assigning a new responsible nurse to a patient. When family members are visiting the patients, the nurses instantly identifies the room where the patient is located.

\section{Phase 3: Message interaction between Health units}

The second challenge for the SAMKAD project was to improve the interaction between KAD and city neighborhoods. Patients arriving at KAD are often senior citizens that receive homecare from the city district they live in. The city districts and KAD exchange information, but KAD also exchange patients and documentation with other health units.

As the city districts have the caretaking responsibility for the citizen, KAD send care messages through the record system after the treatment. These messages are comprehensive, partly unstructured and it is sometimes difficult for the receiver to "grasp" the most important issues regarding the condition of the patient. The city districts called KAD by phone several times in order to understand what the message content really meant. There was a need for improving the interaction through more effective and distinct messages. In cooperation with two city districts Stovner and $\emptyset_{\text {stensjø, SAMKAD created a message }}$ structure in Imatis using ADL-standard and are currently performing a pilot-project on these messages. The ADL structure is simpler than the care messages and easier to standardize using a numeric system to describe the condition of the patient.

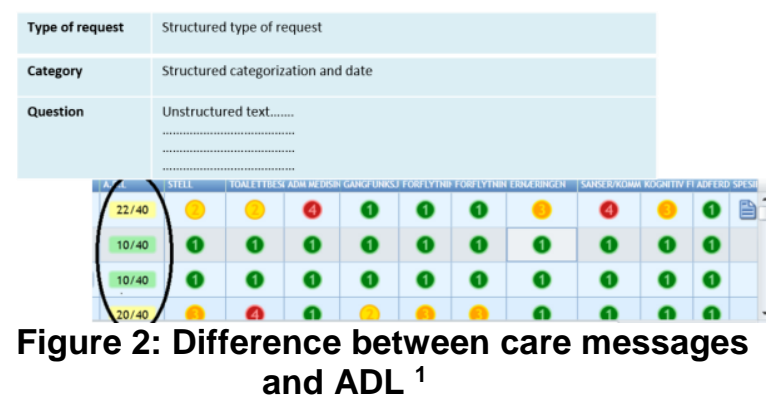

Several informants' expresses positive views on the change: "The standardization of ADL gives us a more systematic description, and less deviation," a nurse said. "It is easier to use", said another and "it is much

\footnotetext{
${ }^{1}$ Activities in Daily Life (ADL), structured into distinct categories like walking ability, medication, cognitive ability, danger of falling, nutrition, etc.
}

easier to immediately identify the important information", according to a third.

In this section we described SAMKADs collective organizational approach where the work processes was analyzed, and improvement areas was identified. The improvements concerned important patient flow processes both within and across hospital units. In section 6 we will elaborate on these issues.

A possible shortcoming in the current installation is the lack of integration between the record system(s) SystemG (city districts) and SystemP (General practitioners) and Imatis. Main suppliers (of SystemG and SystemP) have refused to give access to their interfaces. The ongoing work to enable integration between the record systems and Imatis is done by the municipality, not the suppliers (see lower parts of figure 1). Oslo Municipality has currently initiated a new strategy for "welfare technology", and the SAMKAD innovation project is a part of this, enabling further improvements in the interaction between different Health units and KAD. In 6.4 we address this issue.

\section{Analyzes}

In this section, we will analyze the case using Melao and Pidds [34] four perspectives of business processes. 6.1 is related to findings in Phase 1 in Section 5 in the way that SAMKAD made important use of their existing practices, rules and regulations when they innovated their processes. Through the participation from organizational actors' processes that was relatively easy to improve was identified. 6.2 is based on findings from Phase 2 where the processes identified in Phase 1 is digitalized. Also in complex hospital settings processes that are relatively straightforward exists, and digitalization may in some cases give improvements relatively fast. 6.3 is based on Phase 3 where SAMKAD improved their message exchange with city neighborhoods, and relates to Melao and Pidds connection between internal and external units through interacting feedback loops. 6.4 is derived from the analyzes of the project events, and is particularly based on Phase 2 and 3 where the role of lightweight technology came forward as of significant importance in making the project successful. 


\subsection{Using installed base in process innovation}

At KAD emergency unit, they had significant challenges with the patient flow, and in getting overview of available resources like clinicians, rooms and equipment. They used paper notes to communicate, and walked long distance to deliver them. The improvement process started establishing a detailed overview of all process related aspects. The result was a comprehensive map that became a fundamental and collective entity to identify areas of improvement in at least two ways. First as noted by Melao and Pidd [34], business processes may be social constructs i.e. processes partly made by people with different values, expectations and agendas and special knowledge. In health and educational institutions, autonomy of work is of particular importance, the "installed base" [7] has to be taken into account, as change often happens through a collective analytical process conditioned by negotiations and compromises $[13,33,34]$.

Second, complex "enmeshed" processes may consist of simpler elements that may be improved relatively fast. Melao and Pidds second perspective puts faith in the dynamics and interactive features of processes, where feedback mechanisms are standardized, systematized, and automatized. It is thus most appropriate on well-defined processes that require little adjustment. At KAD the collective approach on the complex map, helped them identifying areas of adjustment, while the electronic whiteboard enabled implementation of required changes.

Table 2: Analyzes Phase 1

\begin{tabular}{|c|c|}
\hline Melao and Pidd & SAMKAD Phase 1 \\
\hline $\begin{array}{l}\text { Business processes as } \\
\text { social constructs i.e } \\
\text { processes as made and } \\
\text { enacted by people } \\
\text { with different values, } \\
\text { expectations and } \\
\text { agendas as well as } \\
\text { special knowledge. }\end{array}$ & $\begin{array}{l}\text { " } 24 \text { hrs at KAD" is made } \\
\text { based on input from } \\
\text { workers, existing rules } \\
\text { and regulations. Peoples } \\
\text { values and expectations } \\
\text { are used as a central } \\
\text { resource for process } \\
\text { innovation. }\end{array}$ \\
\hline $\begin{array}{l}\text { Business processes as } \\
\text { complex dynamic } \\
\text { systems i.e the } \\
\text { dynamics and } \\
\text { interactive features of } \\
\text { processes. }\end{array}$ & $\begin{array}{l}\text { KAD identified } \\
\text { processes that could be } \\
\text { improved, and extended } \\
\text { the understanding of } \\
\text { their own organization. }\end{array}$ \\
\hline
\end{tabular}

\subsection{Lightweight IT in process innovation}

At KAD, the implementation of electronic whiteboards led to improvements on several areas.
First, using the whiteboard for processes of admission and discharge of patients made communication more effective. Second the use of the same technology for cleaning and kitchen personnel to dynamically gain information on what to do and when, improved the preparation of rooms and food. In addition, the visualization of the information on the electronic whiteboards gave a better overview of the patients and the treatment status and consequently improved communication during meetings. Relating to Melao and Pidds perspectives we see that whiteboards has the ability to improve logistics in relatively static operations by sending electronic messages to key actors when something has to be done. Cleaning and foodservices operate relatively independent of patient treatment processes, and can be planned separately. Following Hammers [30] six principles for improvement, KAD is now occupied with the relation between tasks and outcomes; they have partly automated communication so that there is a more effective relation between the process performer and the information receiver. Decisions are immediately displayed on the whiteboard, improved messages have reduced double work, and there is less manual communication on logistics. Integration between systems may further reduce double work.

Table 3: Analyzes Phase 2

\begin{tabular}{|l|l|}
\hline Melao and Pidd & SAMKAD Phase 2 \\
\hline Business processes as & Improve logistics: the \\
deterministic machines: & admission and \\
breaking tasks into well- & discharge of patients, \\
defined operations that & $\begin{array}{l}\text { as well as the cleaning } \\
\text { of rooms and } \\
\text { can be performed }\end{array}$ \\
without deviations. & preparation of food. \\
\hline
\end{tabular}

\subsection{Improving message exchange}

Efficient communication may improve treatment quality. KADs communication with city districts was inefficient. The care messages were comprehensive, and thorough, but the city districts nevertheless needed clarifications. The improved messages, which took the requirements in the interacting feedback loops seriously, led to fewer phone calls, a more standardized and distinct message format, which clarified status when the patient was sent home from KAD. These improvements may lead to releasement of important resources. Second, on a more general level, the SAMKAD project is about improving horizontal processes across hospital units. The complex map " 24 hrs. at KAD" enabled the clinicians to see their role as an actor in a bigger system where patients move between health units. KADs collaboration with fifteen city districts and four 
hospitals requires a deep insight into internal and external conditions for dynamic interaction, and lightweight IT has a promising ability in facilitating this.

Table 4: Analyzes Phase 3

\begin{tabular}{|l|l|}
\hline Melao and Pidd & SAMKAD Phase 3 \\
\hline Business processes as & Improve interaction \\
interacting feedback & through collaborations \\
loops performance and & on standardization. \\
a wider set of & \\
interactions, according & \\
to policies and other & \\
parts of the wider \\
environment which \\
may affect the \\
processes.
\end{tabular}

In summary, KADs combination of a collective approach to understand their challenges (Melao and Pidds second and fourth perspective) was a prerequisite to identify logistical and interactive improvements (perspective one and three)

\subsection{Using lightweight IT in a "bypassing strategy."}

We describe the process at KAD in three steps. First, process innovation, and the technology needed to innovate, challenged the existing regimes, and the resistance from several stakeholders made the implementation of the solution a challenging task. Second, the SAMKAD project decided to establish a lightweight infrastructure, and then third gradually implement a foundation for interaction between lightweight and heavyweight IT. This stepwise interaction is made necessary through the resistance from the existing regime of heavyweight vendors, juridical, economic and political protectors of status quo. The digital infrastructure consisted of a technological portfolio where vendors had long-term contracts, governed by an established regime for maintaining and developing this technology. Although EPR vendors still resist, the success of the installation has made the technological managers in Oslo Municipality more positive towards the integration.

\section{Table 5: Stepwise integration of lightweight infrastructure}

\begin{tabular}{|l|l|l|}
\hline Phase & $\begin{array}{l}\text { Activity and } \\
\text { challenge }\end{array}$ & Solution \\
\hline P1:2014 & $\begin{array}{l}\text { Establish a } \\
\text { process } \\
\text { innovation plan, } \\
\text { and identify }\end{array}$ & $\begin{array}{l}\text { Technological } \\
\text { solution } \\
\text { identified and } \\
\text { apply for funding }\end{array}$ \\
\hline
\end{tabular}

\begin{tabular}{|l|l|l|}
\hline & $\begin{array}{l}\text { relevant } \\
\text { technology. } \\
\text { Resistance from } \\
\text { existing regime. }\end{array}$ & $\begin{array}{l}\text { from research } \\
\text { councils }\end{array}$ \\
\hline $\begin{array}{l}\text { P2: 2015- } \\
\text { 2016 }\end{array}$ & $\begin{array}{l}\text { Prototyping and } \\
\text { implementation } \\
\text { of mobile and } \\
\text { whiteboard } \\
\text { technology. }\end{array}$ & $\begin{array}{l}\text { Establish a } \\
\text { separate } \\
\text { lightweight } \\
\text { infrastructure } \\
\text { and enable } \\
\text { interaction } \\
\text { between KAD } \\
\text { and municipality. }\end{array}$ \\
\hline $\begin{array}{l}\text { P3: Late } \\
\text { 2016- }\end{array}$ & $\begin{array}{l}\text { Integrating } \\
\text { heavyweight and } \\
\text { lightweight } \\
\text { infrastructure. } \\
\text { Heavyweight } \\
\text { vendors resist. }\end{array}$ & $\begin{array}{l}\text { Oslo } \\
\text { Municipality } \\
\text { establish a } \\
\text { solution (ITAS in } \\
\text { figure 1) for } \\
\text { "low-scale" } \\
\text { integration } \\
\text { between } \\
\text { heavyweight and } \\
\text { lightweight IT. }\end{array}$ \\
\hline
\end{tabular}

\section{Discussion}

In this study, we build on a case from an emergency unit in Oslo to investigate the role of lightweight IT in supporting process innovation within an established e-health information infrastructure. We frame our study within the field of information infrastructures, but use insights from business process innovation to develop our argument.

Despite Hammer and Champys [29, 30] lack of differentiation between different types of organizational configurations and processes, they have basic innovation advices that are still very valid. Melao and Pidds [34] perspective enable us to identify different types of business processes conditioned by the respective differences in organizational purposes. They provide guidance for identifying internal and external processes that can be improved quite quickly while they at the same time retain the awareness of horizontal flow and capacity utilization. An additional difference between early BPR literature and the later literature from Melao and Pidd is that organizational culture, which consists of 'processes shaped by beliefs, values, expectations and previous experience' [34:120] has to be recognized as valuable. The literature on Information infrastructure [7] have framed and conceptualized these pre-existing resources, rules, regulations, processes, and systems as installed base. The installed base should as far as possible be used as a resource not as a threat to the process innovation initiatives. 
We add to the existing literature on information infrastructures by providing two contributions.

First, our findings show that broad organizational participation in the analytical phase in process innovation initiatives gives collective energy and inspiration to identify areas of improvement. In Section 5, Phase 1 and Section 6.1 we described how existing processes and regulations was used as a point of departure. In contrast with Hammer [30] which talks about "obliterate" and to "start from scratch", we claim that the installed base can be a rich source for process innovation, i.e. it enables creative use and reuse of existing structures and knowledge in the efforts to establish and improve horizontal processes. This will reduce the resistance towards change as the organizational actors find that certain aspects of their work may be improved. The literature on information infrastructures [7, 13, 33] carries this insight, but frame it as incremental and path dependent development. To keep the steam and motivation up among the organizational actors, innovation sometimes requires development to be performed a bit faster [15]. This leads us to the second contribution.

Second, we find that lightweight IT have certain strengths which is important for process innovation. Lightweight IT improves logistics within an organization, and interaction between organizations. In addition, the long term and slow development progress of heavyweight projects where it sometimes takes years from analyzes to implementation may cause collective and individual energy to dissolve and disappear [19, 31]. In section 5, phase 2 and 3 we described the relatively fast acquisition, implementation and adoption of innovative technology in improving distinct logistical processes, processes related to communication between clinical personnel, and interaction between health units. The lightweight supplier provided a prototype very fast and extended the energy into the actual implementation project. In section 6.2, we also described how principles from the early BPR literature $[29,30]$ might be helpful in identifying slow and time-consuming manual processes.

We can understand the strength of lightweight IT through three aspects, which facilitates process innovation. First through the "artefact" which enables improved information overview through an aggregated visualization of patient status and position in relation to the horizontal flow. Second the ability of lightweight IT suppliers to quickly provide assistance in the efforts to plan, implement and further develop the solution, as well as providing a technology which can bypass the existing arrangements if necessary. Third, the ability to commercialize and make the technology universally accessible gives hospital organizations the possibility to acquire and re-use successful configurations established elsewhere.

Based on this we also shed light on the technical modelling aspects of process innovation. We humbly suggest a step-by-step evolution through three phases of implementation of lightweight IT at an emergency unit. In section 5, Phase 1-3 we described the acquisition process, and figure 1 gives an overview of the outcome. In section 6.4 we suggest that lightweight technology may be implemented separately and that integration with the existing digital infrastructure may be done afterwards. The ability of lightweight IT to operate independently or loosely coupled to the patient record systems may contribute to the realization of parts or all of the process innovation ambitions. A separate acquisition process may speed up the innovation initiative and enable the organization to improve their flow processes faster.

Through these two contributions we extend information infrastructure theory by providing a process innovation lens governed by the knowledge regime of lightweight IT, and consequently provide a faster and more adaptable view of innovation in information infrastructures. Second we also add to the literature on information infrastructure $[7,18,33]$ and electronic whiteboards $[16,17,20,24]$ in that we not only focus on improvements within particular clinical departments, but on cross-sectional information flow and the added requirements this entails.

In conclusion reflecting on our findings, we do not claim that lightweight technologies solve all organizational and technological challenges in the health systems. There is a broad range of health treatment trajectories that requires a broader, more elaborate and more secure approach. There is however a tendency that lightweight IT may solve some of the challenges, in our case the logistical processes and interaction between health units. In addition, our findings origin is an emergency unit in Oslo, Norway, and may not fit complex emergency units in bigger cities. This may particularly apply to our suggested implementation strategy. Further studies should shed light on this issue.

\section{References}

[1] Norwegian Directorate of Health: https://ehelse.no/Documents/Nasjonale\%20prosjekter/Nasj onal\%20handlingsplan\%20for\%20e-helse.pdf, 2016

[2] G. F. Anderson, B. K. Frogner, and U. E. Reinhardt: "Health spending in OECD countries in 2004 an update", Health Aff. 26(5), 1481-1489, 2007

[3] A. Salazar, B. Ortiga, J. Escarrabill, and X. Corbella, "Emergency department complaints: A 12 year study in a University hospital" Annals of Emergency Medicine, 44(4) 2004 
[4] Norwegian Ministry of Health. Prep 125. https://www.regjeringen.no/contentassets/b218612046c84 d89bec57fa537ea57f/nn no/pdfs/prp201420150125000dddpdfs.pdf, 2015 [5] J. De Vries, and Huijsman, R., "Supply chain management in health services: an overview," Supply Chain Management: An International Journal, Vol. 16, 159 $-165,2011$

[6] W.A.M. Van Lent, E. M. Sanders, and W. H. Van Harten, "Exploring improvements in patient logistics in Dutch hospitals with a survey". BMC Health Services Research, 12, 232-240, 2012

[7] O. Hanseth and K. Lyytinen, "Design theory for Dynamic complexity in Information infrastructures: the case of building internet." JIT, 25(1), 1-19, 2010 [8] E. Monteiro, "Scaling Information Infrastructure: The Case of Next-Generation IP in the Internet, The Information Society", 14:3, 229-245, 1998

[9] George, A.L., and Bennett, A., Case Studies and Theory Development in the Social Sciences, MIT Press, 2005

[10] B. Bygstad, "Generative innovation: A Comparison of lightweight and heavyweight IT", JIT, 1-14, 2016

[11] M. Lacity, and L. Willcocks, Robotic Process Automation at Telefonica O2, MIS Quarterly Executive 15(1): 21-35, 2015

[12] L. Willcocks, M. Lacity, and A. Craig, The IT function and Robotic Process Automation.

http://eprints.lse.ac.uk/64519/1/OUWRPS_15_05_publish $\underline{\text { d.pdf }}$

[13] M. Grisot, O. Hanseth, and A. Thorseng, "Innovation Of, In, On Infrastructures: Articulating the role of Architecture In Information Infrastructure", Journal of the AIS, vol.15, 197-219, 2014

[14] Norwegian Board of Health Supervision: https://www.helsetilsynet.no/upload/Publikasjoner/rapport r2016/helsetilsynetrapport1_2016.pdf , 2016

[15] Davenport, T., Process innovation: reengineering work through information technology, Harvard Business School press, 1993

[16] G. Fitzpatrick, and G. Ellingsen, “A Review of 25 Years of CSCW Research in Healthcare: Contributions, Challenges and Future Agendas." Computer Supported Cooperative Work 22:609-665, 2013

[17] D. Aronsky, I. Jones, K. Lanaghan, and C. M Slovis, "Supporting patient care in the emergency department with a computerized whiteboard system". J.Am.Med. Inf. Assoc.15(2),184-194, 2008

[18] Ciborra C. et al, "From Control to Drift - The Dynamics of Corporate Information Infrastructures," Oxford University Press, 2000

[19] E. P. Piening, "Insights into the process dynamics of innovation implementation", Public Management Review, vol 13, issue 1, p 127-157, 2011

[20] M. Hertzum, and J. Simonsen, J, "Visual overview Oral detail: The use of an emergency-department

Whiteboard", Int. J. Human-Computer Studies 82, 21-30, 2015

[21] A. Tang, J. Lanir, S. Greenberg, and S. Fels, "Supporting transitions in work: informing large display Application design by understanding whiteboard use",
Proceedings of the Conference on Supporting Group Work. ACMPress, NYC ,149-158, 2009

[22] P. Bjørn, and M. Hertzum, "Artefactual multiplicity: a study of emergency- department whiteboards", Comput.Support.Coop.Work 20, 93-121, 2011

[23] H. J. Wong, M. Caesar, S. Bandali, J. Agnew, and H. Abrams, "Electronic inpatient whiteboards: improving multidisciplinary communication and coordination of care", Int.J.Med.Inf. 78 (4), 239-247, 2009

[24] M. Hertzum, "Electronic emergency-department whiteboards: A study of clinicians' expectations and experiences", International journal of medical informatics 80, 618-630, 2011

[25] Office of the Auditor General of Norway.: https://www.riksrevisjonen.no/rapporter/Documents/2015 2016/Samhandlingsreformen.pdf, 2015

[26] P.F. Hu, Y. Xiao, D. Ho, C. F. Mackenzie, H. Hu, R, Voigt, and D. Martz, "Advanced visualization platform for Surgical operating room coordination: distributed video Boardsystem”, Surg.Innov.13(2), 129-133, 2006 [27] M. Hertzum, and J, Simonsen, "Work-practice Changes associated with an electronic emergency Department whiteboard," Health Informatics Journal, 19, 46-60, 2013

[28] D. J. France, S. Levin, R. Hemphill, K. Chen, D. Rickard, R. Makowski, I. Jones, and D. Aronsky, "Emergency physicians' behaviors and workload in the presence of an electronic whiteboard", International Journal of Medical Informatics 74, 827-837, 2005

[29] Hammer, M. and Champy, J., Reengineering the corporations, Harper NYC, 1993

[30] M. Hammer, "Reengineering work: don't automate, Obliterate", Harvard Business Review, 1990

[31] C. Kelly, and A. Young, "Promoting innovation in Healtcare", Future Healthcare Journal Vol 4, 121-5, 2017

[32] D. D. Dobrzykowski, "Examining Heterogeneous Patterns of Electronic Health Records Use: A Contingency Perspective and Assessment", International Journal of Healthcare Info Systems and Informatics, 7(2), 2012

[33] M. Aanestad, and T. B. Jensen, "Building nation-wide information infrastructures in healthcare through modular implementation strategies", Journal of Strategic Information Systems, 161-176, 2011

[34] N. Melao, and M. Pidd, "A conceptual framework for understanding business processes and business modelling". Information Systems Journal 10(2), 105-129, 2000

[35] Helsedirektoratet: https://helsedirektoratet.no/samhandlingsreformen, 2016 [36] L. Mathiassen, "Designing Engaged Scholarship:From Real-World Problems to Research Publications," Engaged Management Review, Vol. 1, 2017

[37] B. Bygstad, and B. E. Munkvold, "Exploring the role of informants in Interpretive Case Studies Research in IS", Journal of Information Technology, 1-14, 2010

[39] M. Romøren, R. Pedersen, R. Førde, "En pasient, to verdener - samhandling mellom sykehjemsleger og sykehusleger", Tidskr Nr Legeforen nr. 3; 137-193, 2017 